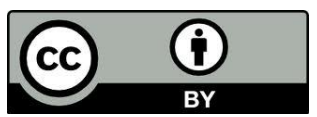

\title{
"UMBANDAS": SEGMENTAÇÃO E LUTA DE REPRESENTAÇÕES NAS PÁGINAS DE UMA PUBLICAÇÃO UMBANDISTA
}

\author{
"Umbandas" segmentation and fight the pages of representations of a \\ republication umbandista \\ André de Oliveira Pinheiro \\ Mestre em História Cultural pela Universidade Federal de Santa Catarina (UFSC). Membro do \\ Núcleo Paranaense de Pesquisa em Religião (Nupper). \\ imprensa.comunica@gmail.com
}

\begin{abstract}
RESUMO: Este artigo trata da segmentação existente na Umbanda. A partir da noção de campo umbandista, baseada no conceito de campo religioso, de Pierre Bourdieu, analisamos, de maneira breve, as várias "Umbandas": diferentes segmentos ou formas diferenciadas que os adeptos utilizam para pensar e praticar a religião umbandista.

Para esta análise, temos como principal fonte o periódico Revista Espiritual de Umbanda, além dos livros escritos por autores que pertencem a diversas vertentes umbandistas.

Palavras-chave: Umbanda; religiões afro-brasileiras; religiões e religiosidades; religiosidade popular; campo religioso.
\end{abstract}

ABSTRACT: This text analyzes the segmentation in Umbanda religion. Starting from the Umbanda field notion, based on religious field concept, by Pierre Bourdieu, we analyze, briefly, the many "Umbandas": the several segments, or different ways wich Umbanda devotee use to think about and practice this religion.

To this work, the main source is the jornal Revista Espiritual de Umbanda and some books written by members of several Umbanda sects.

Keywords: Umbanda; African-brazilian religions; religions and religiousness; popular religiousness; religious field. 
Este artigo se propõe a analisar, de maneira breve, a luta de representações ${ }^{1}$ que ocorre no interior do campo religioso umbandista ${ }^{2}$. Para isso, temos como principal fonte a imprensa umbandista, mais especificamente a Revista Espiritual de Umbanda, além de livros escritos por autores que representam diferentes segmentos umbandistas.

Com abrangência nacional, a Revista Espiritual de Umbanda circulou de 2003 a 2008. Totalizando 20 edições publicadas nesse período, pode ser considerada como o mais bem-sucedido projeto informativo voltado para as religiões afro-brasileiras de que se tem notícia. Em 2009, os mesmos editores da Revista Espiritual de Umbanda passaram a publicar a Revista Espírita de Umbanda, que ainda está em circulação.

Ao estudar a relação entre imprensa e História, Bethânia Corrêa Mariani (1993, p. 33) define o discurso jornalístico como parte do processo histórico de seleção dos acontecimentos que serão recordados no futuro, fixando sentidos para os acontecimentos noticiados e engendrando um modo (possível) de recordação do passado:

O discurso jornalístico tanto se comporta como uma prática social produtora de sentidos como também, direta ou indiretamente, veicula as várias vozes constitutivas daquele imaginário. Em suma, o discurso jornalístico (assim como qualquer outra prática discursiva) integra uma sociedade, sua história. Mas ele também é história, ou melhor, ele está entranhado de historicidade.

Dessa forma, o discurso jornalístico produzido pelo projeto editorial da Revista Espiritual de Umbanda pode ser considerado produtor de sentidos. Dele resultam representações, tradições e até mesmo tensões dentro do próprio campo religioso

\footnotetext{
${ }^{1}$ A noção de representação, segundo Roger Chartier (2002) apud Pinheiro (2009, p. 20), estabelece três modalidades de relações com o mundo social. Na primeira, a realidade é construída de diferentes formas pelos diversos grupos que integram uma sociedade. Na segunda, estão as práticas que resultam no reconhecimento de uma identidade social, com uma maneira própria de ser no mundo, significando simbolicamente um estatuto ou uma posição. Já a terceira modalidade diz respeito às formas institucionalizadas e objetivas, em virtude das quais "representantes" marcam de modo visível e perpétuo a existência do grupo.

${ }^{2} \mathrm{O}$ conceito de campo religioso, desenvolvido por Pierre Bourdieu (2005), é o espaço onde se desenrola o conflito. É nesse campo, que não pode ser definido como bom ou ruim, que os diferentes grupos ou indivíduos lutam pela afirmação de uma produção e a descaracterização, desqualificação de outra. Para a legitimação de determinado pensamento, identidade ou discurso, é necessário que haja consenso em torno da sua valorização.
} 
umbandista, o que se reflete nas referências aos diversos segmentos da Umbanda que podem ser encontradas nos textos publicados pela revista.

$\mathrm{O}$ vigésimo e último número da Revista Espiritual de Umbanda chegou às bancas em novembro de 2008. Nessa época, o centenário da Umbanda era comemorado pelas diversas correntes ou escolas umbandistas que defendem o mito fundador desta religião protagonizado pela entidade Caboclo das Sete Encruzilhadas e pelo médium Zélio Fernandino de Moraes, em 1908³. Nas páginas da referida edição (REVISTA ESPIRITUAL DE UMBANDA, 2008, p. 3), a defesa desse mito fundador aparece logo no editorial, com referência direta ao segmento umbandista denominado "Umbanda Branca":

Em cem anos de culto de Umbanda Branca, após 36.525 dias de anunciada, em 15 de novembro de 1908 sob a roupagem fluídicoespiritual de um caboclo brasileiro, perguntamos:

Quantos templos seguem o ritual de Umbanda Branca do Caboclo das Sete Encruzilhadas, que faz 100 anos no dia 15 de novembro de 2008 ?

Além da expressão "Umbanda Branca", citada acima, podemos encontrar na revista outras denominações associadas ao nome da religião, como "Umbanda Esotérica", "Umbanda Popular" e "Umbanda Sagrada". Cada um desses adjetivos agregados ao nome "Umbanda" refere-se a uma forma de conceber, enxergar a religião e também de praticar os rituais - ou, segundo a conceituação de Roger Chartier, a uma das modalidades de representação.

Patrícia Birman (1985, pp. 25-26) já havia chamado a atenção para toda a diversidade dentro da própria Umbanda, inclusive com as diversas tentativas de organização burocrática e unificação doutrinária:

No plano da organização social, a religião umbandista pode ser considerada um agregado de pequenas unidades que não formam um conjunto unitário. (...) Cada pai-de-santo é senhor no seu terreiro, não havendo nenhuma autoridade superior por ele reconhecida. Há, portanto, uma multiplicidade de terreiros autônomos, embora estejam

${ }^{3}$ Sobre essa questão, ver: PINHEIRO, 2009, pp. 38-60. 
unidos na mesma crença, havendo também um esforço permanente por parte dos líderes umbandistas no sentido de promover uma unidade tanto doutrinária quanto na organização.

A autora ainda constatou a diversidade de doutrinas e concepções religiosas que podem ser encontradas sob a mesma denominação de "Umbanda". E, ao tratar desta questão, Birman (1985, pp. 26-27) não deixou de considerar as diferentes religiões que, em sua construção sincrética, forneceram elementos para a formação da religião umbandista:

Entre os terreiros são encontradas diferenças sensíveis no modo de se praticar a religião. Tais diferenças, contudo, se dão num nível que não impede a existência de uma crença comum e de alguns princípios respeitados por todos. Há, pois, uma certa unidade na diversidade.

A diversidade se expressa nas várias e reconhecidas influências de outros credos na umbanda. Encontramos adeptos de umbanda que praticam a religião em combinação com o candomblé, com o catolicismo, que se dizem também espíritas, absorvendo os ensinamentos de Kardec e, entre estes, as variações continuam: centros que aceitam determinados princípios do candomblé e excluem outros, que se vinculam a uma tradição por muitos ignorada etc. Não há limites na capacidade do umbandista de combinar, modificar, absorver práticas religiosas existentes, dentro e fora desse campo fluido denominado "afro-brasileiro".

Denominamos campo umbandista este grande espaço chamado Umbanda, que traz em seu interior diferentes formas de pensar ou praticar esta religião, ou - por que não dizer? - diferentes "Umbandas". Claramente inspirada no conceito de campo religioso desenvolvido por Pierre Bourdieu (2005), a expressão campo umbandista foi utilizada por Lísias Nogueira Negrão (1996).

O campo umbandista seria, portanto, o espaço onde conviveriam e entrariam em luta as diferentes representações da Umbanda, cada uma procurando maior legitimação 
e captação de capital simbólico entre os filhos-de-fé ${ }^{4}$ umbandistas, em detrimento das demais. São as diferentes "Umbandas" disputando entre si para ver qual é mais "pura", a mais verdadeira, a mais autêntica ou até mesmo a que tem mais força espiritual.

A “unidade na diversidade” observada por Patrícia Birman (1985, p. 27) entre os umbandistas torna-se possível porque estes "desenvolveram formas próprias de lidar com essas características da sua religião". Ao tratar do espaço que denominamos campo umbandista, a autora chama a atenção para três fatores: segmentação, dispersão e multiplicidade. Estes elementos, de acordo com Birmam (1985, p. 27), se combinam, de alguma forma, com a unidade, a doutrina e a hierarquia:

Essas combinações estão claramente presentes nas formas pelas quais organizam a multiplicidade de santos num conjunto inteligível e como também conseguem, apesar da segmentação, reunir todos os fiéis numa mesma doutrina.

E esta "multiplicidade de santos" não passou despercebida pelos editores da Revista. Na $14^{\mathrm{a}}$ edição, de 2006, foi publicado o texto "Sincretismo Religioso: Faz Sentido?”, que ocupa uma página da Revista Espiritual de Umbanda (2006, p. 29). Tratando especificamente do sincretismo religioso afro-católico, o texto começa por mencionar as estratégias utilizadas pelos escravos a partir da necessidade de adaptação para burlar a proibição do culto às divindades africanas. Após esta introdução, é colocada a pergunta: "Mas, e hoje, temos necessidade disto? A resposta, infelizmente, não é tão simples...".

Mais adiante, o(s) próprio(s) redator(es) do texto se encarrega(m) da resposta (REVISTA ESPIRITUAL DE UMBANDA, 2006, p. 29):

Em verdade, ao analisarmos profundamente o sincretismo religioso chegamos à conclusão que, teologicamente, o mesmo não faz sentido. Por quê? Pelo simples fato de que os Orixás, como forças espirituais,

\footnotetext{
${ }^{4}$ Filho-de-fé: uma das formas utilizadas, no meio umbandista, para designar o adepto da Umbanda.

${ }^{5}$ Em várias oportunidades, ao conversar com dirigentes de templos umbandistas que visitei, perguntei qual seria o tipo de Umbanda que estes praticavam. Na maioria das vezes, a resposta foi "Umbanda pura". Esta definição pode ao mesmo tempo significar pureza em relação a raízes e tradições ou pureza espiritual. Tal resposta pode claramente ser lida como uma tentativa de legitimar os rituais que praticam, e, ao mesmo tempo, desqualificar os outros existentes, que seriam menos "puros".
} 
sempre existiram, ou seja, não passaram a "existir" quando do surgimento da Igreja Católica e de seus santos. (...)

Por outro lado, na visão prática, o sincretismo religioso ainda é necessário, apesar, de como já dissemos, não ter sentido teologicamente falando. Acontece que a Umbanda abarca vários graus de consciência, abraçando tanto o intelectual quanto o analfabeto.

Acreditamos que com o passar do tempo e a evolução espiritual das humanas criaturas, estes artifícios utilizados pelo Astral Superior não serão mais necessários, visto que os véus que encobrem o entendimento pleno das coisas espirituais cairão completamente.

Na parte inferior da mesma página, abaixo da matéria, um pequeno box resume os elementos do sincretismo religioso presentes da Umbanda. A explicação da Revista Espiritual de Umbanda (2006, p. 29), que, curiosamente, inclui a "porcentagem" da influência de cada religião no culto umbandista, é a seguinte:

Sincretismo Africano: Orixás, cantos, instrumentos de som, guias (colares), comidas, bebidas, trabalhos, ervas sagradas, orações, oferendas etc. Representa uma média de 65 a $70 \%$, dependendo do templo.

Sincretismo Indígena: Culto aos Caboclos, culto aos antepassados, ervas sagradas, defumações, bebidas etc. Representa uma média de 15 a 20\%. Na parte africana o culto aos Caboclos já aparece - Nação Angola.

Sincretismo Católico: Santos católicos, orações etc. Representa de 2 a $3 \%$ e tem sido combatido. Mas se vêem, ainda hoje, umbandistas que o defendem, apesar de a Umbanda ter forte fundamento africano e indígena. $\mathrm{O}$ que existe ainda é herança da imposição no tempo da escravidão. O Candomblé já o combateu em grande parte.

Sincretismo Oriental: Defumações, pontos riscados (cabalísticos), amuletos, astrologia, meditações etc.

Sincretismo Espírita: orações, passes, doutrina etc. 
O texto não explica os critérios utilizados para definir o peso de cada religião no sincretismo umbandista. Também evidencia ou sugere falta de fundamentação ao atribuir somente 2 ou 3\% de influência ao Catolicismo e nenhuma porcentagem ao Espiritismo. As duas religiões demonstram ter grande importância na maior parte dos rituais de Umbanda. No caso do Catolicismo, as referências estão presentes nas imagens de santos, nas orações e também nos nomes de alguns templos umbandistas. Quanto ao Espiritismo, há a crença na reencarnação e vários fundamentos doutrinários utilizados para explicar os fenômenos ocorridos na Umbanda, as preces dirigidas a espíritos cultuados no Espiritismo, como Bezerra de Menezes, e a denominação "espírita", largamente utilizada por umbandistas quando estes se definem religiosamente ou nomeiam suas casas de culto, com denominações como "Tenda Espírita" e até mesmo “Centro Espírita”.

Referências a algumas das "Umbandas" - variedades de cultos dentro da religião umbandista - aparecem no texto "Das Macumbas Cariocas ao Movimento Umbandista", incluído no número 17 da Revista Espiritual de Umbanda (2007, p. 30). Logo de início, há o endosso ao já citado mito fundador da religião: “A oficialização da religião de Umbanda, com o advento do Caboclo das Sete Encruzilhadas, em 15 de novembro de 1908, deu origem ao Movimento Umbandista".

Em seguida, o texto afirma que a Umbanda sempre estivera aberta a variadas influências de cultos já existentes no Rio de Janeiro, "como os Candomblés Nagô ou Bantu", com predomínio das "Nações Bantos - Congo e Angola".

Ainda em sua parte inicial, o texto, que ocupa quatro páginas da edição, fala das diferentes denominações que a Umbanda já recebia logo após o seu surgimento (REVISTA ESPIRITUAL DE UMBANDA, 2007, p. 30):

O culto original, ao qual o Caboclo das Sete Encruzilhadas dera o nome de Umbanda, alguns anos depois já recebia outras denominações: Umbanda Omoloko e Umbanda de Pretos-Velhos (com a presença maior de elementos das religiões africanas) ou Umbanda Branca, com traços mais fortes da influência do Espiritismo, ou ainda Umbanda de Caboclos, com ritos próximos aos da Pajelança Indígena. Mais adiante, ainda há o surgimento de uma Umbanda com influências do Esoterismo e da Teosofia: Umbanda Esotérica e Umbanda Iniciática. 
Toda essa mistura de influências gerou muitas correntes, com doutrinas próprias, ritos e preceitos diferenciados de acordo com o fundamento de cada casa e de seu Guia-Chefe.

Além da Revista Espiritual de Umbanda, vários livros - de autores umbandistas ou de pesquisadores que não pertencem a esta religião - registram as diferentes denominações da Umbanda.

Em seu "Dicionário Histórico das Religiões", Antonio Carlos do Amaral Azevedo (2002, p. 357) divide a Umbanda em duas vertentes:

Umbanda popular - preserva fortes traços das raízes africanas e tem a presença da quimbanda - para este autor, ritual que trabalha com exus e pomba-giras, podendo ser "cruzada" (misturada) com o Candomblé Angola; predomina entre seus fiéis a classe média baixa.

Umbanda branca ou esotérica - tende a afastar-se da tradição africana, evitando quaisquer cerimônias que envolvam sacrifícios de animais, adotando ritos mágicos europeus e divulgando um mito de origem ligado à Atlântida e ao antigo Egito, o que a torna mais aberta à presença de brancos e membros de classes mais altas.

Olga Gudolle Cacciatore (1988, pp. 242-243), no "Dicionário de Cultos Afrobrasileiros", divide a Umbanda de forma semelhante. De acordo com a autora, esta religião compreende:

Umbanda Esotérica, iniciática ou cabalística - com doutrina de difícil compreensão para as massas populares.

Umbanda popular - com teorias mais simples e acessíveis.

Olga Cacciatore, no entanto, conceituou a Umbanda branca como algo à parte:

Umbanda branca - só pratica magia branca e extirpou de seus rituais tudo que fosse chocante contra a ordem instituída pela sociedade dos brancos, como iniciação sangrenta, trabalhos de magia negra etc.

A autora aponta ainda outra variedade, que, embora pareça guardar algumas semelhanças, é, no entanto, diferente da Umbanda branca:

Umbanda de branco - culto umbandista muito próximo do Kardecismo e que usa roupa e sapatos brancos, mesa, sobre assoalhos de madeira. Também chamada 
Umbanda de Cáritas, porque abre as sessões com a Prece de Cáritas, do Espiritismo de Kardec e se preocupa muito em praticar a caridade material e espiritual.

Além destas divisões, retiradas de dicionários, há ainda outras, que também agregam outros nomes ao substantivo "Umbanda" e podem ser encontradas nas páginas dos livros dos próprios escritores umbandistas:

Umbanda Branca - trabalha basicamente com as linhas de caboclos e pretosvelhos, unindo seus mistérios, magias e sabedoria. É uma religião pura, extremamente organizada, tratada com seriedade e que obedece a normas sagradas. Empenhada em prestar a caridade. A definição é dos autores Domingos Forchezatto, Maria Alice Giannoni e Maria Elidia dos Santos (1999, p. 21).

Nos livros "Trabalhos de Umbanda-canjerê" e "Sacramentos da Umbanda Mística", o escritor umbandista Josef Ronton traz explicações sobre as seguintes variedades de Umbanda:

Umbanda-Canjerê - Canjerê é uma palavra de origem africana que quer dizer “dançando se faz um trabalho para resolver algo". Mas há quem traduza o canjerê como sendo dança de macumba. Sendo uma ou outra coisa, o que importa é o seu resultado satisfatório. O canjerê estabelece com a roda e a cantiga uma corrente cósmica e de forças sutis da natureza, capaz de resolver problemas de ordem material e espiritual aos quais estamos sujeitos e dos quais queremos nos livrar (RONTON, 1994, p. 9).

Umbanda mística - tem por base a religião e a fé. Diz o místico que, quando todos os recursos materiais se esgotarem, restará a fé. Em outras palavras: quando toda a sabedoria humana e todos os remédios falharem, a fé faz o milagre (RONTON, 1989, p. 13).

Umbanda esotérica - estuda as forças sutis da natureza, pelas quais Deus, seus anjos, orixás, gênios e espíritos se manifestam. Estuda também a astrologia, a parapsicologia, a grafologia, a quiromancia, as propriedades medicinais e espirituais das plantas, a simbologia que envolve pontos riscados, talismãs, amuletos (RONTON, 1989, p. 13-14). 
Umbanda kardecista - seus adeptos se limitam a doutrinar espíritos que se encontram perturbando alguém. Para isso, ocupam o médium como receptáculo do sofredor, para que este seja orientado e guiado no caminho da luz. Também chamada de "linha branca de Umbanda" (RONTON, 1989, p. 14).

O escritor A. G. Anselmo (1940) traz a sua conceituação de Linha Branca de Umbanda:

Linha Branca de Umbanda - Umbanda é uma palavra de sentido oculto. Entretanto, permite-nos a tradução de seu sentido em "Luz de Deus", ou ainda "trabalho de luz que vem de Deus". Umbanda é a sabedoria divina entre os homens. Umbanda é a fusão de todas as religiões do Universo. Umbanda é também chamada, e com razão, "Linha Branca de Umbanda". Linha, com o significado de sistema religioso. Branca, para afirmar o que ela pretende: branco é o oposto do negro; branco é Luz, é o Bem; negro é treva, é o $\mathrm{Mal}^{6}$.

Outros rituais relacionados à Umbanda também têm suas definições elaboradas por escritores vinculados à religião:

Almas e Angola - ritual praticado em Santa Catarina e que teve sua origem no Rio de Janeiro. É, na realidade, uma ramificação da Umbanda, porém com particularidades que o aproximam muito do Candomblé. Em Almas e Angola existem, por exemplo, obrigações internas denominadas feituras de Orixá ou camarinhas. Nessas atividades o médium tem sua cabeça raspada, fica recluso no Terreiro, deitado numa esteira por sete dias e, como ocorre no Candomblé, oferece menga - sangue de animais - aos Orixás. Na Umbanda tradicional isso não ocorre, pelo menos naquela que segue a linha de Zélio F. de Moraes. A definição é do escritor umbandista Giovani Martins (2006, p. 23).

Em seu livro "Umbanda Omolocô”, Caio de Omulu (2002, p. 33) explica:

\footnotetext{
${ }^{6}$ Importante não deixar passar despercebida a conotação pejorativa do negro ao final desta definição. Apesar de referir-se à cor negra, pode ser estendido - e se fazer presente como causa ou consequência da discriminação racial. Até mesmo porque a Umbanda dita branca, como podemos ver em algumas definições, está entre as mais afastadas dos elementos africanos.
} 
Umbanda Omolocô - intersecção clara entre o que vulgarmente se chama de Candomblé e a Umbanda. Ressurgiu através de Tancredo da Silva Pinto, na contramão da desafricanização da Umbanda. É um amálgama no qual, por um lado, se encontra uma proximidade muito forte com os ritos do Candomblé, em relação aos orixás e seus fundamentos; por outro, com a Umbanda, no que diz respeito ao seu trabalho com as entidades espirituais (caboclos, pretos-velhos, crianças etc.). Daí se terem usado também as expressões "Candomblé de Caboclo" e "Umbandomblé" para identificá-lo.

A curiosa expressão "Umbandomblé", por sua vez, aparece como verbete no “Novo Dicionário Banto do Brasil”, do pesquisador Nei Lopes (2003, p. 219):

Umbandomblé - Termo pejorativo usado para designar os terreiros pouco ortodoxos da tradição dos orixás. De Umbanda + Candomblé.

No editorial de seu $10^{\circ}$ número, a Revista Espiritual de Umbanda (2005, p. 3) também se posicionou em relação ao Umbandomblé. O título não deixa dúvidas quanto ao teor do texto: “Umbandomblé - Onde está a Ética?". A legenda da foto também é direta: "O Sincretismo é uma realidade, Umbandomblé é um equívoco".

No editorial, é possível ler:

Da prática da junção de Candomblé e Umbanda surge o que chamamos de "Umbandomblé". Isso não é sincretismo, é apenas a migração de práticas religiosas que nada tem a ver com o Ritual de Umbanda, muitas vezes, puro exibicionismo. Aceitar rituais ou filosofias e inseri-las na Umbanda tem seu limite no bom senso de cada sacerdote.

O texto, assinado por Pedro Miguel e Espíritos amigos, é concluído da seguinte maneira (REVISTA ESPIRITUAL DE UMBANDA, 2005, p. 3):

Irmãos de fé, precisamos entender que é simples a Lei, não é medíocre e não tem como base o cinismo. A Lei é uma só e o homem é equilibrado em sua natureza e postura evolutiva, a idolatria à matéria é que o tira de seu caminho. 
Reflitam e acabem com as couraças da matéria. Umbandomblé: isso não é Umbanda nem Candomblé. O alicerce da nossa Umbanda é a caridade, firmada na Lei Natural e Evolutiva do "Amar ao próximo como a si mesmo", do "É dando que se recebe".

Saravá Jesus, Saravá Oxalá,

Saravá, Buda, Saravá, Ghandi...

Além do sincretismo e do Umbandomblé, a respeito dos quais a Revista se posiciona de forma desfavorável por meio de seus textos, há ainda a Quimbanda, outra palavra que aparece sempre relacionada à Umbanda. No meio umbandista, geralmente se atribuem à Quimbanda dois significados mais comuns. $\mathrm{O}$ primeiro deles refere-se simplesmente aos trabalhos com exus e pombas-giras ${ }^{7}$, entidades consideradas da "linha da esquerda". Nesse caso, a Quimbanda é uma prática que integra o ritual de Umbanda. No segundo significado, o termo Quimbanda designa um culto autônomo, independente e até mesmo oposto à própria Umbanda: é como se fosse uma Umbanda que admitisse ou fosse voltada para o mal, para trabalhos de magia negra.

Em relação a esse segundo significado, é exemplar a definição do escritor umbandista Lourenço Braga. A começar pelo título de sua obra "Umbanda - Magia Branca e Quimbanda - Magia Negra”, publicada em 1942 e que, antes, havia sido apresentada como tese no $1^{\circ}$ Congresso Brasileiro de Espiritismo de Umbanda, em 1941. Logo na abertura do primeiro capítulo, Braga (1942, p. 9) esquematiza a maneira como, de acordo com ele, se divide o Espiritismo:

\section{CAPÍTULO I}

\section{DIVISÃO DO ESPIRITISMO}

Lei de Kardec:

- Espiritismo doutrinário, filosófico e científico.

Lei de Umbanda:

\footnotetext{
${ }^{7}$ Pomba-gira é o equivalente feminino ao Exu na Umbanda. Normalmente associada à vida boêmia, às vezes com a prostituição, é tratada como uma mulher "da noite". Muito procurada por consulentes para resolver problemas amorosos.
} 
- Espiritismo - Magia Branca.

Lei de Quimbanda:

- Espiritismo - Magia Negra.

Outro escritor umbandista, Altair Pinto, em seu "Dicionário da Umbanda", também define a Quimbanda como magia negra. Citado na capa do Dicionário como presidente da "Tenda de Umbanda Com Jesus no Coração", Pinto (s/d, p. 159) não deixa de relacionar a magia negra ao Candomblé, provavelmente na tentativa de desqualificá-lo, indício da tensão existente entre essas duas religiões afro-brasileiras:

QUIMBANDA - A mesma coisa que Magia Negra, ou melhor o Candomblé que surgiu, entre nós, primeiramente na Bahia, oriundo de uma mistura de rituais praticados pelos escravos da África.

A Quimbanda aparece como magia negra - e, desta vez, mais vinculada às influências africanas - também no já citado "Dicionário de Cultos Afro-brasileiros" de Olga Cacciatore (1988, pp. 218-219), que traz uma extensa definição:

Quimbanda - Linha ritual da Umbanda que pratica a magia negra. Essa linha é assim chamada pelos umbandistas de "linha branca", pois os praticantes se dizem apenas umbandistas. A Quimbanda, influenciada mais diretamente pelos negros bantos - cabindas, benguelas, congos, angolas, moçambiques etc. - chegados dos portos africanos ao Rio de Janeiro, não fugiu ao sincretismo. (...) Mediante encomenda realizam feitiços ou contra-feitiços, visando favorecer ou prejudicar determinadas pessoas. (...) As giras de Exu são frequentes, realizadas comumente a partir da meia-noite de $6^{\text {a }}$ feira. Exus e Pombagiras diversos "baixam", dançam, fumam charutos ou cigarrilhas, bebem aguardente (marafo), dizem gentilezas ou palavrões aos assistentes e dão consultas sobre saúde ou problemas pessoais. (...) A Quimbanda cultua muito Omolu, orixá ligado à terra e à morte, considerando-o "Rei do Cemitério". No cemitério é feita uma parte da iniciação de muitos quimbandeiros, devendo o iniciando deitar 
algumas horas sobre um túmulo, entre velas e cânticos do Pai ou Mãede-santo e iniciados do terreiro, tendo de cumprir, antes e depois, diversas obrigações. (...) São muito usados os "trabalhos" com pólvora, pós e ervas mágicos, dentes e unhas, cabelos (animais e humanos), galos e galinhas pretos (que são, às vezes, estraçalhados entre os dentes do iniciado incorporado com um exu (...). Os despachos são colocados em encruzilhadas em cruz (macho) ou em T (fêmea), com velas, flores e fitas vermelhas, pipocas, milho etc. e animais de duas ou quatro patas, de penas ou pelos pretos ou vermelhos, em alguidares de barro, não sendo, porém, negativos todo os despachos de rua. (...) Os terreiros quase sempre são pobres, localizados em morros ou locais afastados.

Por sua vez, o pesquisador Nei Lopes (2003, p. 187), em seu "Novo Dicionário Banto do Brasil", traz a seguinte explicação para o termo Quimbanda:

QUIMBANDA - (1) Linha ritual da umbanda que trabalha principalmente com exus. (2) Sacerdote de cultos de origem banta Do quimbundo kimbanda, sacerdote e médico ritual correspondente ao quicongo nganga. (...) Estranhamente, no Brasil, a quimbanda (primeira acepção) é tida como linha de práticas também maléficas. Terá a palavra nesta acepção alguma relação com o quicongo kimbanda, víbora? ${ }^{8}$

Exus, magia negra e quimbanda são temas bastante controversos. Normalmente, as manifestações de exus e pombas-giras e práticas como o sacrifício de animais contribuem para uma visão pejorativa a respeito da Umbanda e de outras religiões afrobrasileiras. Por isso, tais assuntos são tratados com muito cuidado - muitas vezes, são até mesmo evitados - e geram intensas polêmicas entre os próprios umbandistas. Provavelmente por esse motivo, somente em sua $5^{\text {a }}$ edição, publicada em 2004, a Revista Espiritual de Umbanda abriu espaço de forma mais direta para o assunto. Algo bastante compreensível, uma vez que seus editores, ao defenderem uma concepção de

\footnotetext{
${ }^{8}$ Citados nesta referência, Quimbundo e Quicongo são duas línguas bantas, de acordo com o referido Dicionário, de autoria de Nei Lopes.
} 
Umbanda mais próxima à tradição de Zélio de Moraes, podem ter experimentado receio ou preocupação em abordar o tema e decidido fazê-lo somente após transmitirem aos leitores as representações sobre a Umbanda que julgam mais adequadas. Após as quatro edições iniciais, é possível que estivessem seguros quanto a isso.

Em seu $5^{\circ}$ número, a Revista Espiritual de Umbanda (2004) dedicou 14 páginas ao assunto Quimbanda (também grafado Kimbanda, na publicação). A abordagem se divide na publicação de quatro textos dos escritores umbandistas Osvaldo Omotobatalá, Decelso, Aluízio Fontenelli e W.W. da Matta e Silva.

$\mathrm{Na}$ capa, a chamada, bastante discreta, anuncia: "Kimbanda na visão dos escritores Decelso, W.W. da Matta e Silva, Aluízio Fontenelli e Osvaldo Omotobatalá”. Por outro lado, a mesma capa tem como única ilustração a figura de Jesus, com chamada para a matéria "Entrevista com o Sacerdote Juruá: Culto Umbanda com Jesus - Contém Pôster de Oxalá” (REVISTA ESPIRITUAL DE UMBANDA, 2004, p. 1).

Exercitando o mesmo sincretismo religioso que mais tarde seria desaprovado no já citado texto da $14^{\mathrm{a}}$ edição, o Oxalá anunciado na capa é o próprio Jesus, e seu pôster está nas páginas centrais da Revista (2006, pp. 34-35). Antes disso, há também o texto “Oxalá Supremo: Jesus”, de autoria do Professor José Ribeiro de Souza, respeitado escritor de livros sobre Umbanda e Candomblé. Curiosamente, “Oxalá Supremo: Jesus" ocupa as páginas 16 e 17, exatamente entre os textos dedicados à Quimbanda.

Uma rápida consulta a outros números da Revista Espiritual de Umbanda é suficiente para constatar que, geralmente, quando há textos diferentes sobre o mesmo tema, estes são publicados em sequência. Assim como a inclusão de um texto sobre Oxalá ou Jesus entre os escritos sobre Quimbanda, chama a atenção a publicação do pôster e também o destaque na capa para a ilustração de Jesus. O espaço na capa, inclusive, pode ser considerado desproporcional, se for comparado o número de páginas em que aparece cada um dos temas: o texto "Oxalá Supremo: Jesus" e o pôster, juntos, ocupam oito páginas, bem menos do que as 14 páginas dedicadas aos textos sobre Quimbanda.

A desproporção no espaço da capa, a publicação do pôster e a inserção de um texto sobre Jesus intercalado com o tema Quimbanda podem ser interpretados como uma estratégia para desviar o foco e amenizar, de certa forma, a importância e o espaço dedicados à Quimbanda nesta edição. É como se a presença de Oxalá/Jesus 
neutralizasse o mal simbolizado pela Quimbanda. Além disso, os editores pareciam ter a intenção de manter em evidência Oxalá, símbolo maior da tradição umbandista defendida pela publicação.

Para tratar das "Umbandas" - maneira como podemos nos referir à segmentação e às diferentes representações presentes no campo umbandista - utilizamos como principal fonte as 20 edições da Revista Espiritual de Umbanda. Dessa forma, acreditamos ter contribuído para reafirmar a importância da pesquisa sobre os mass media e da análise dos órgãos de comunicação como elementos que auxiliam a ampliar a compreensão sobre as diversas religiões e religiosidades.

\section{Referências:}

ANSELMO, A. G. Catecismo Espiritualista da Linha Branca de Umbanda. Rio de Janeiro, Jornal do Commercio, 1940.

AZEVEDO, A. C. do A. Dicionário Histórico de Religiões. Rio de Janeiro: Nova Fronteira, 2002.

BIRMAN, P. O que é Umbanda. São Paulo: Abril Cultural / Brasiliense, 1985. Coleção Primeiros Passos.

BOURDIEU, P. A Economia das Trocas Simbólicas. São Paulo: Perspectiva, 2005. BRAGA, L. Umbanda - Magia Branca e Quimbanda - Magia Negra. Rio de Janeiro: Edições Spiker, 1942.

CACCIATORE, O. G. Dicionário de Cultos Afro-brasileiros. Rio de Janeiro: Forense Universitária, 1988.

CHARTIER, R. À Beira da Falésia: a História entre Certezas e Inquietude. Porto Alegre: Ed. Universidade/UFRGS, 2002.

FORCHEZATTO, D.; GIANNONI, M. A.; SANTOS, M. E. dos. Umbanda Branca e Cristã. Campinas, SP: R. Vieira, 1999.

LOPES, N.. Novo Dicionário Banto do Brasil. Rio de Janeiro: Pallas, 2003.

MARIANI, B. S. C. Os primórdios da imprensa no Brasil (ou: de como o discurso jornalístico constrói a memória). In: ORLANDI, E. P. (org.). Discurso Fundador: a formação do país e a construção da identidade nacional. Campinas: Pontes, 1993. 
MARTINS, G. Ritual de Almas e Angola em Santa Catarina. Florianópolis: Edição do Autor, 2006.

NEGRÃO, L. N. Entre a Cruz e a Encruzilhada: Formação do Campo Umbandista em São Paulo. São Paulo: Editora da Universidade de São Paulo, 1996.

OMULU, C. de. Umbanda Omolocô: liturgia, rito e convergência (na visão de um adepto). São Paulo: Editora Ícone, 2002.

PINHEIRO, A. de O. Revista Espiritual de Umbanda: mito fundador, tradição e tensões no campo umbandista. 2009, 124 f. Dissertação (Mestrado em História) Universidade Federal de Santa Catarina, Florianópolis: UFSC, 2009.

PINTO, A.. Dicionário da Umbanda. Rio de Janeiro: Editora Eco, sem data. $3^{\text {a }}$ edição.

REVISTA ESPIRITUAL DE UMBANDA. Nº 05. São Paulo: Escala, 2004.

REVISTA ESPIRITUAL DE UMBANDA. Nº 10. São Paulo: Escala, 2005.

REVISTA ESPIRITUAL DE UMBANDA. Nº 14. São Paulo: Escala, 2006.

REVISTA ESPIRITUAL DE UMBANDA. Nº 17. São Paulo: Escala, 2007.

REVISTA ESPIRITUAL DE UMBANDA. Nº 20. São Paulo: Escala, 2008.

RONTON, J. Trabalhos de Umbanda-Canjerê. São Paulo: Ícone Editora, 1994.

RONTON, J. Sacramentos da Umbanda Mística. São Paulo: Ícone Editora, 1989.

Recebido: 08/03/2012

Received: 03/08/2011

Aprovado: 02/07/2012

Approved: 07/02/2012 